\title{
The Benefit of Vitamin D Therapy on Psychological Aspects in Children and Adolescents in Western Saudi Arabia
}

Lama Khaled Arfaj, Suzan Abu Alainain and Abdulmoein Eid Al-Agha*

Pediatric Department, King Abdulaziz University Hospital, Jeddah 21589, Saudi Arabia

*Corresponding author: Abdulmoein Eid Al-Agha, Professor of Pediatric Endocrinology, King Abdulaziz University Hospital, Jeddah 21589, Saudi Arabia, Tel: 00966505590459; Fax: +96626403841, E-mail: aagha@kau.edu.sa

Received date: June 03, 2017; Accepted date: June 26, 2017; Published date: June 30, 2017

Copyright: (C) 2017 Arfaj LK, et al. This is an open-access article distributed under the terms of the Creative Commons Attribution License, which permits unrestricted use, distribution, and reproduction in any medium, provided the original author and source are credited.

\begin{abstract}
Background: Vitamin D deficiency is a major public health problem worldwide, including in children of Saudi Arabia. Vitamin D has numerous beneficial skeletal and non-skeletal physiological effects. Vitamin D is not only essential for bone health, but also promotes proper brain development and functioning. Vitamin D also serves many important functions, such as promoting calcium absorption and reducing inflammation.
\end{abstract}

Aim: To investigate the relationship between vitamin D deficiency and psychological impacts in children and adolescents, and to determine whether vitamin D therapy has beneficial psychological effects in this population.

Study design: This cross-sectional study was conducted in Jeddah, Saudi Arabia. The sample included 181 young children and adolescents between 2 and 18 years of age ( 88 females, 93 male) from various regions of the city. Relevant data were collected during clinic interviews. Data were analyzed using a chi-square test for nominal data. Interview data were used to compare pre- and post-vitamin $\mathrm{D}$ treatment factors.

Results: Psychological manifestations associated with vitamin D deficiency were commonly seen between 6-12 years of age $(40.9 \%), 2-6$ years of age $(38.1 \%)$, and $12-18$ years of age $(21.0 \%)$. Males $(51.4 \%)$ exhibited higher rate of deficiency when compared to females $(48.6 \%)$, although this relationship was not statistically significant ( $p$ value $=0.441$ ). Most males and females displayed insufficient vitamin $D$ levels. A significant improvement in psychological symptoms was noted with vitamin $D$ therapy ( $p$-value $<0.05$ ).

Conclusion: A correlational relationship between vitamin D deficiency and psychological problems was revealed in children and adolescents, through comparison of improvements psychological issues following vitamin $D$ therapy.

Keywords: Vitamin D; Deficiency; Psychosis; Children; Adolescents

\section{Introduction}

Vitamin D deficiency is an important health problem in both developed and developing countries, and is highly prevalent among children and adolescents worldwide, especially in Saudi Arabia [1]. The prevalence of vitamin D deficiency in Saudi Arabia among children and adolescents is striking, with $95.3 \%$ of the population found to experience vitamin D deficiency [2]. Vitamin D influences the body in terms of both skeletal and non-skeletal effects, including increasing the ability to absorb calcium, which assists in regulating the level of calcium and phosphorus in the body. It further protects against many health problems, such as depression and cancer, and contributes to the treatment of certain medical conditions, such as diabetes and obesity.

Vitamin D plays a vital role in improving psychological aspects, especially depression, vitamin D therapy's effect on many diseases (e.g., diabetes, hypertension, cancer, Seasonal Affective Disorder, multiple sclerosis, and obesity) [3]. Many factors can affect vitamin D status, such as genetic, adiposity, skin pigmentation, ethnicity, age, season, clothing that results in lack of skin exposure to the sun, and use of sunscreens [4]. Several studies have discuss that there is an essential factor associated with chronic health conditions, including mental health, while others have shown no relationship and insufficient evidence for an association between vitamin $\mathrm{D}$ and mental health.

The importance of vitamin D effects on central nervous system (CNS) has been shown in both healthy and psychiatric populations $[5,6,7]$. The current study aimed to investigate the relationship between vitamin $\mathrm{D}$ deficiency and the psychological impacts in children and adolescents. Additionally, the current study sought to determine whether vitamin D therapy had beneficial effects on psychological issues faced by this population.

\section{Materials and Methods}

\section{Ethics}

The research and ethics committee at King Abdulaziz University Hospital in Jeddah approved the study.

\section{Research design}

This cross-sectional study collected data through children or parent's interviews in an endocrine clinic at King Abdulaziz University. 


\section{Sampling technique}

The study population selected consisted of a random set of young males and females. Inclusion criteria included all pediatric age groups between 2 to 18 years. Vitamin D deficiency was initially documented by laboratory investigations. Sample was interviewed a second time following vitamin $\mathrm{D}$ treatment and normal vitamin $\mathrm{D}$ results. Exclusion criteria were, children younger than 2 years or older than 18 years of age, those who were not treated with vitamin D therapy, those with normal mental health, and those on antipsychotic medications. The study subjects were randomly selected from endocrine clinic at King Abdulaziz University, Jeddah, Saudi Arabia.

\section{Tools for data collection}

The data were collected in a clinic, via interview, over the course of one month (August 2016). The interview questions contained two parts. The first was pre-vitamin $\mathrm{D}$ treatment, which included the behavior and psychological condition of the participant, the rate of vitamin $\mathrm{D}$ found through vitamin analysis, and how often the participant was exposed to the sun. Specifically, the following questions were asked: "Does your child/adolescent feel sad?" "Does your child/adolescent exhibit appetite change?" "Is your child/ adolescent unsocial?" "Does your child/adolescent feel fatigue?" "Does your child/adolescent exhibit low focus?" "Does your child/adolescent exhibit suicidal thoughts?" "Does your child/adolescent exhibit difficulty in making decisions?" "Does your child/adolescent exhibit sluggish motion?" "Does your child/adolescent exhibit speech difficulties?" "Does your child/adolescent cry for no discernable reason?" and "Does your child/adolescent exhibit developmental delays?" The second segment of data collection occurred post-vitamin $\mathrm{D}$ treatment, which included vitamin $\mathrm{D}$ supplements and sun exposure. Data were collected by medical students from endocrine clinic at King Abdulaziz University, Jeddah, Saudi Arabia.

\section{Laboratory tests}

The following normal ranges for serum levels of hydroxyvitamin D $25(\mathrm{OH}) \mathrm{D}$, phosphorous, calcium, and alkaline phosphates were used as a reference. For vitamin $\mathrm{D}$, a serum concentration of 51-75 nmol/L was considered as the normal range, with insufficiency/deficiency defined by a concentration $\leq 25-50 \mathrm{nmol} / \mathrm{L}$. For calcium levels, a concentration of $2.2-2.62 \mathrm{mmol} / \mathrm{L}$ was considered normal, with hypocalcaemia defined as $<2.2 \mathrm{mmol} / \mathrm{L}$. For phosphorus, a concentration of 0.8-1.6 mmol/L was considered normal, with a high serum concentration defined as $>1.6 \mathrm{mmol} / \mathrm{L}$. For alkaline phosphates has normal range defined as $50-136 \mathrm{mmol} / \mathrm{L}$ and the high serum level was defined as $>136 \mathrm{mmol} / \mathrm{L}$ [8]. All was done in lab by complete blood count.

\section{Statistical analysis}

Data were entered, coded, and analyzed using the Statistical Package for Social Sciences (SPSS), version 22. Analysis was conducted by finding the relationships and percentages between those exhibiting a lack of vitamin $\mathrm{D}$, and the improvements measured after taking treatment, using a chi-square test for nominal data. The data are presented in both Table 1 and Figures 1-3. Simple descriptive statistics are reported as proportions for qualitative variables. The results were considered significant with p-values less than 0.05 .

\begin{tabular}{|c|c|c|c|c|c|}
\hline \multirow[b]{2}{*}{ Question 1} & \multicolumn{2}{|c|}{ Before treatment } & \multirow{2}{*}{$\begin{array}{l}\text { Question } 2 \\
\text { Yes n (\%) }\end{array}$} & \multicolumn{2}{|c|}{ After treatment } \\
\hline & Yes n (\%) & No n (\%) & & No n (\%) & \\
\hline Does your child/adolescent feel sad? & $66(36.5 \%)$ & $115(63.5 \%)$ & Is your child/adolescent still feeling sad? & $16(8.8 \%)$ & $50(27.6 \%)$ \\
\hline Is your child/adolescent unsocial? & $69(38.1 \%)$ & $112(61.9 \%)$ & Is your child/adolescent still unsocial? & $13(7.2 \%)$ & $18(9.9 \%)$ \\
\hline $\begin{array}{l}\text { Does your child/adolescent exhibit appetite } \\
\text { change? }\end{array}$ & $94(51.9 \%)$ & $87(48.1 \%)$ & Has your child/adolescent's appetite improved? & $76(42 \%)$ & $18(9.9 \%)$ \\
\hline Does your child/adolescent feel fatigue? & $74(40.9 \%)$ & $107(59.1 \%)$ & Is your child/adolescent still feeling fatigue? & $15(8.3 \%)$ & $59(32.6 \%)$ \\
\hline $\begin{array}{l}\text { Does your child/adolescent exhibit low } \\
\text { focus? }\end{array}$ & $85(47 \%)$ & $96(53 \%)$ & Has your child/adolescent's focus improved? & $20(11 \%)$ & $65(35.9 \%)$ \\
\hline $\begin{array}{l}\text { Does your child/adolescent exhibit suicidal } \\
\text { thoughts? }\end{array}$ & $12(6.6 \%)$ & $169(93.4 \%)$ & $\begin{array}{l}\text { Is your child/adolescent still exhibiting suicidal } \\
\text { thoughts? }\end{array}$ & $2(1.1 \%)$ & $10(5.5 \%)$ \\
\hline $\begin{array}{l}\text { Does your child/adolescent exhibit difficulty in } \\
\text { making decisions? }\end{array}$ & $73(40.3 \%)$ & $108(59.7 \%)$ & $\begin{array}{l}\text { Does your child/adolescent still exhibit difficulty in } \\
\text { making decisions? }\end{array}$ & $21(11.6 \%)$ & $53(29.3 \%)$ \\
\hline $\begin{array}{l}\text { Does your child/adolescent exhibit sluggish } \\
\text { motion? }\end{array}$ & $41(22.7)$ & $140(77.3 \%)$ & $\begin{array}{l}\text { Does your child/adolescent still exhibiting } \\
\text { sluggish motion? }\end{array}$ & $9(5 \%)$ & $32(17.7 \%)$ \\
\hline $\begin{array}{l}\text { Does your child/adolescent exhibit speech } \\
\text { difficulties? }\end{array}$ & $29(16 \%)$ & $152(84 \%)$ & $\begin{array}{l}\text { Does your child/adolescent still exhibit speech } \\
\text { difficulties? }\end{array}$ & $9(5 \%)$ & $20(11 \%)$ \\
\hline $\begin{array}{l}\text { Does your child/adolescent cry for no } \\
\text { reason? }\end{array}$ & $70(38.7 \%)$ & $111(61.3 \%)$ & Is your child/adolescent still crying for no reason? & $13(7.2 \%)$ & $57(31.5 \%)$ \\
\hline $\begin{array}{l}\text { Does your child/adolescent exhibit } \\
\text { developmental delays? }\end{array}$ & $79(43.6 \%)$ & $102(56.4 \%)$ & $\begin{array}{l}\text { Does your child/adolescent still exhibit } \\
\text { developmental delays? }\end{array}$ & $71(39.2 \%)$ & $8(4.4 \%)$ \\
\hline
\end{tabular}

Table 1: Summary of percentages before and after vitamin D therapy. 
Page 3 of 4

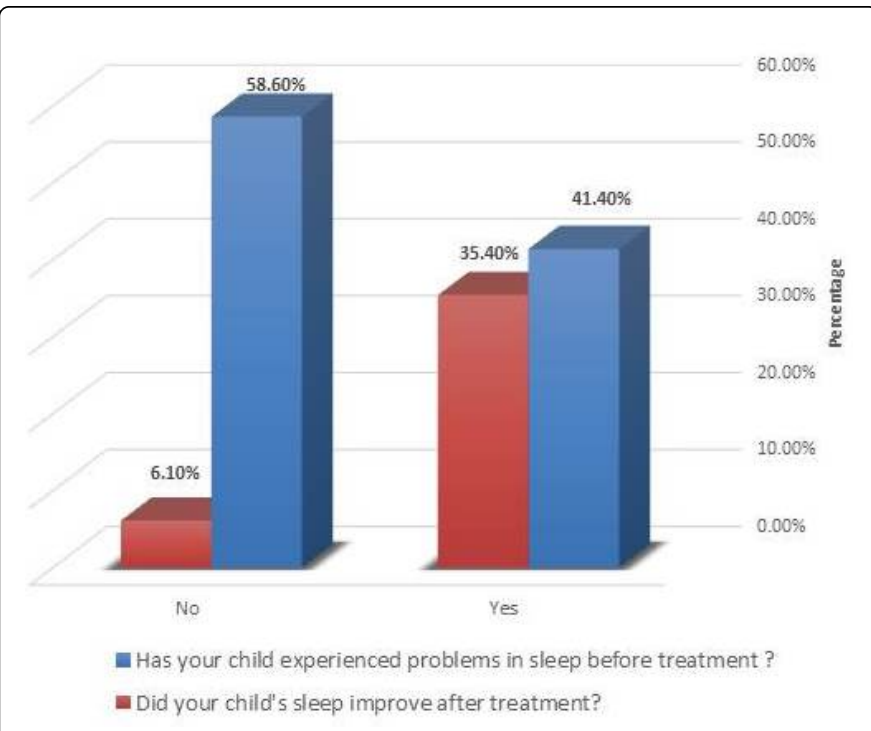

Figure 1: Comparison of children's sleeping problems before and after vitamin D therapy.

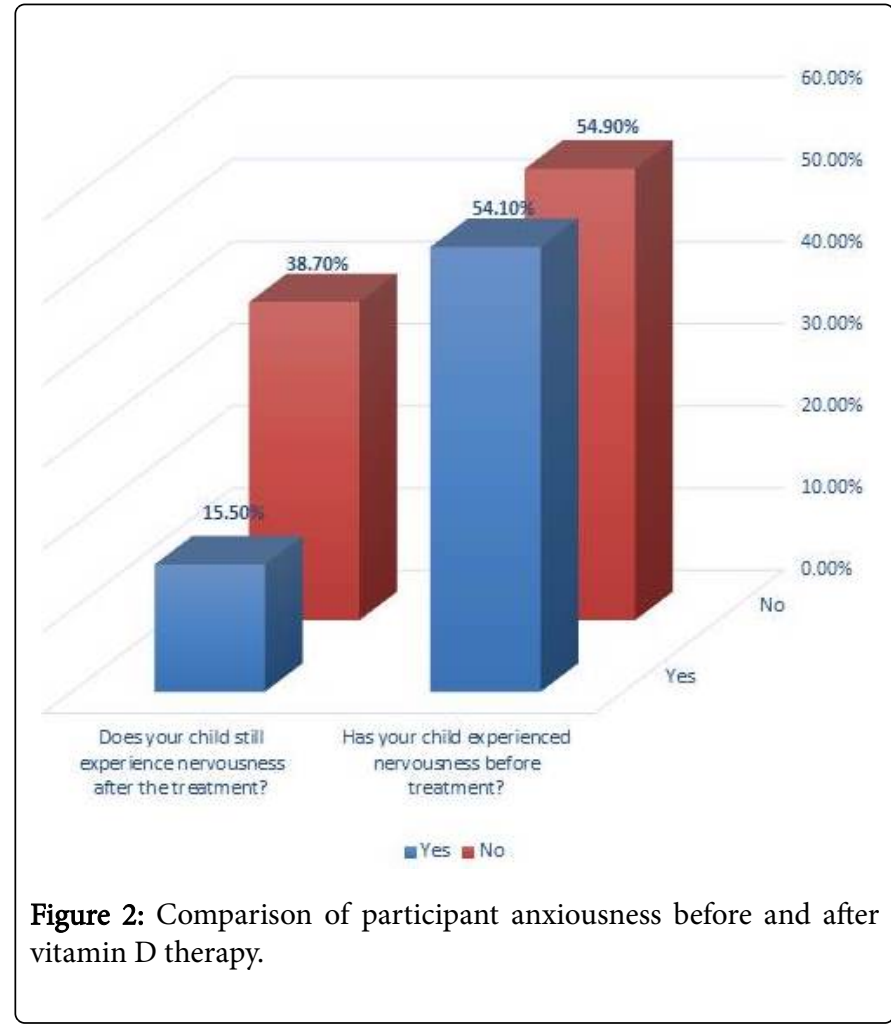

\section{Results}

We revealed no significant relationship among psychological problems and vitamin D deficiency, in terms of age or gender, in participants. Both males and females displayed insufficient vitamin D levels; $84 \%$ of the children suffered from vitamin D insufficiency, while $16 \%$ suffered from vitamin $\mathrm{D}$ deficiency, found through vitamin $\mathrm{D}$ analysis.

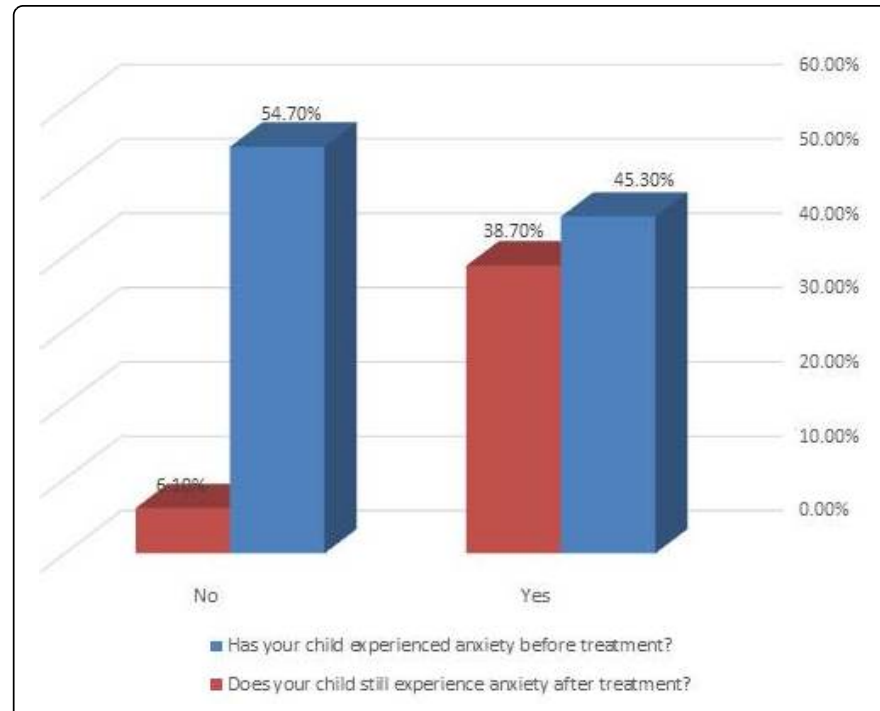

Figure 3: Comparison of participant experienced anxiety before and after vitamin $\mathrm{D}$ therapy.

A significant relationship was revealed with sleeping problems, nervousness, depression, unsocial nature, appetite change, and fatigue ( $\mathrm{p}$-value $=0.0001)$. According to the data collected, $63(84 \%)$ of participants exhibited sleeping problems, but demonstrated improvement after treatment, $11(14.7 \%)$ demonstrated no improvement, and the remaining did not exhibit this problem. Furthermore, $70(71.4 \%)$ displayed symptoms of nervousness that improved after treatment, $28(28.6 \%)$ did not improve, and the remaining did not exhibit this problem. In terms of depression, 50 (75.8\%) of participants who exhibited these symptoms demonstrated improvement after treatment, $16(24.2 \%)$ did not improve, and the remaining did not exhibit these symptoms. Next, 56 (81.2\%) participants exhibited an unsocial nature that improved after treatment, whereas 13 (18.8\%) did not improve; the remaining did not exhibit this problem. Furthermore, 76 (80.9\%) participants displayed appetite changes that improved after treatment, 18 (19.1\%) did not improve, and the rest did not exhibit this problem. Finally, 59 (79.7\%) participants exhibited fatigue that improved after treatment, 15 (20.3\%) did not improve, and the rest did not exhibit this problem.

A noticeable improvement was measured in most of psychological problems after completion of vitamin D therapy.

\section{Discussion}

Vitamin D deficiency has significant medical and psychological consequences. All human tissues have vitamin D receptors, including the brain, heart, muscles, and immune system. In addition to its wellknown role in calcium absorption, vitamin $\mathrm{D}$ activates genes that regulate the immune system and release neurotransmitters (e.g., dopamine, serotonin) that affect brain function and development. Researchers have found vitamin D receptors on a handful of cells located in regions in the brain-the same regions that are linked with depression [9].

In 2010, a study of 29 males and 75 females (12-18 years old) reported that vitamin D insufficiency was present in $38 \%$ of participants, and the association between vitamin $\mathrm{D}$ deficiency and 
psychotic features was substantial $(\mathrm{p}<0.009)$. The $\mathrm{p}$-value of the association for adolescents with psychotic features with lower vitamin D levels was 0.04 [10]. Additionally, a medical school in Oregon demonstrated that low vitamin $\mathrm{D}$ is related to psychiatric disorders in children. Children with mental dysfunction were $50 \%$ more likely to have severe vitamin D deficiency. Furthermore, in 2012 a study in a case-series was done, with the mean serum $25(\mathrm{OH}) \mathrm{D}$ in the depressed adolescents displaying $41 \mathrm{nmol} / \mathrm{L}$ at baseline and $91 \mathrm{nmol} / \mathrm{L}(\mathrm{p}<0.001)$ after supplementation. Basal 25(OH) D levels correlated positively with well-being $(\mathrm{p}<0.05)$. After vitamin $\mathrm{D}$ supplementation, well-being increased $(\mathrm{p}<0.001)$ and there was a significant improvement in eight of the nine items in the vitamin D deficiency scale, including depressed feeling $(p<0.001)$, irritability $(p<0.05)$, tiredness $(p<0.001)$, mood swings $(p<0.01)$, sleep difficulties $(p<0.01)$, weakness $(p<0.01)$, and ability to concentrate $(\mathrm{p}<0.05)$. More recently, $39 \%$ of 1095 Iranian school students (10-18 years old) were found to have vitamin D insufficiency. The odds of reporting feelings of anger, sadness, poor sleep quality, anxiety, depression, and worry were 1.5 to 1.8 times greater for vitamin $\mathrm{D}$ insufficient children and adolescents, when compared to those with normal vitamin $\mathrm{D}$ levels $(\mathrm{p}<0.05)$, but not with violent behaviors $(\mathrm{p}>0.05)$.

The findings of the present study reveal the relationship between vitamin $\mathrm{D}$ deficiency and psychological problems in children and adolescents. Children and adolescents who exhibited a vitamin D deficiency and psychological dysfunction were compared before and after vitamin D therapy. Results indicate that most participants demonstrated improved psychological symptoms following vitamin $\mathrm{D}$ therapy. Therefore, when treating this group of children, it would be beneficial to return vitamin $\mathrm{D}$ levels to normal, in an effort to improve symptoms associated with deficiency, including those related to psychological problems, prior to beginning any additional psychological treatment. Both males and females displayed insufficient vitamin D levels; $84 \%$ of participants exhibited vitamin D insufficiency, while $16 \%$ exhibited vitamin D deficiency. A significant relationship was revealed with sleeping problems, nervousness, sadness, unsocial nature, appetite change, and fatigue ( $\mathrm{p}$-value $=0.0001$ ).

\section{Conclusion}

We revealed a relationship between vitamin $\mathrm{D}$ and psychological problems, in children and adolescents, by comparing the improvement of psychological problems after vitamin D therapy.

\section{Recommendation}

Parents should feed their children foods fortified with vitamins. If they notice any irregular psychological symptoms, a vitamin $\mathrm{D}$ analysis should be conducted regularly to check vitamin D levels for their children/adolescents.

\section{Acknowledgments}

The authors are grateful for the essential cooperation of statistical analyst Ghras Jamil Softah, whose amazing efforts contributed to this study. The authors are also grateful to all the parents who participated in the interviews in the clinic.

\section{References}

1. Huh SY, Gordon CM (2008) Vitamin D deficiency in children and adolescents: epidemiology, impact and treatment. Rev EndocrMetabDisord 9: 161-170.

2. Al Shaikh AM, Abaalkhail B, Soliman A, Kaddam I, Aseri K, et al. (2016) Prevalence of vitamin D deficiency and calcium homeostasis in Saudi children and adolescents. J Clin Res Pediatr Endocrinol 8: 461-467.

3. "Vitamin D". University of Maryland Medical Center.

4. Tsiaras WG, Weinstock MA (2011) Factors influencing vitamin D status. Acta Derm Venereol 91: 115-124.

5. Gracious BL, Finucane TL, Friedman-Campbell M, Messing S, Parkhurst MN (2012) Vitamin D deficiency and psychotic features in mentally ill adolescents: A cross-sectional study. BMC Psychiatry 12: 38.

6. Cannell J (2011) Vitamin D levels in children with psychiatric disorders.

7. Ataie-Jafari A, Qorbani M, Heshmat R, Ardalan G, Motlagh ME, et al. (2015) The association of vitamin D deficiency with psychiatric distress and violence behaviors in Iranian adolescents: the CASPIAN-III study. J Diabetes Metab Disord 14: 62.

8. Al-Agha AE, Mahmoud AF, Alshein AA, Bukhari NH, Alaama MA, et al. (2016) Correlation among Bone Health Profile, Vitamin D Status and Body Weight among Children and Adolescents in the Western Region of Saudi Arabia. Journal of Patient Care 2: 3.

9. James M. Greenblatt (2011) Psychological Consequences of Vitamin D Deficiency.

10. Högberg G, Gustafsson SA, Hällström T, Gustafsson T, Klawitter B, et al. (2012) Depressed adolescents in a case-series were low in vitamin D and depression was ameliorated by vitamin D supplementation. Acta Paediatr 101: 779-783. 